\title{
Feasibility of task-sharing with community health workers for the identification, emergency management and referral of women with pre-eclampsia, in Mozambique
}

Esperança Sevene ${ }^{1,2^{*}}$ (D) Helena Boene ${ }^{1}$, Marianne Vidler ${ }^{3}$, Anifa Valá ${ }^{1}$, Salésio Macuacua ${ }^{1}$, Orvalho Augusto ${ }^{1,4}$, Quinhas Fernandes ${ }^{5}$, Cassimo Bique ${ }^{5,6}$, Eusébio Macete ${ }^{1,5}$, Mohsin Sidat ${ }^{4}$, Peter von Dadelszen ${ }^{7}$ and Khátia Munguambe ${ }^{1,4} \mathrm{CLIP}$ Feasibility Working Group

\begin{abstract}
Background: Maternal mortality is an important public health problem in low-income countries. Delays in reaching health facilities and insufficient health care professionals call for innovative community-level solutions. There is limited evidence on the role of community health workers in the management of pregnancy complications. This study aimed to describe the feasibility of task-sharing the initial screening and initiation of obstetric emergency care for pre-eclampsia/eclampsia from the primary healthcare providers to community health workers in Mozambique and document healthcare facility preparedness to respond to referrals.

Method: The study took place in Maputo and Gaza Provinces in southern Mozambique and aimed to inform the Community-Level Interventions for Pre-eclampsia (CLIP) cluster randomized controlled trial. This was a mixed-methods study. The quantitative data was collected through self-administered questionnaires completed by community health workers and a health facility survey; this data was analysed using Stata v13. The qualitative data was collected through focus group discussions and in-depth interviews with various community groups, health care providers, and policymakers. All discussions were audio-recorded and transcribed verbatim prior to thematic analysis using QSR NVivo 10. Data collection was complemented by reviewing existing documents regarding maternal health and community health worker policies, guidelines, reports and manuals.

Results: Community health workers in Mozambique were trained to identify the basic danger signs of pregnancy; however, they have not been trained to manage obstetric emergencies. Furthermore, barriers at health facilities were identified, including lack of equipment, shortage of supervisors, and irregular drug availability. All primary and the majority of secondary-level facilities (57\%) do not provide blood transfusions or have surgical capacity, and thus such cases must be referred to the tertiary-level. Although most healthcare facilities (96\%) had access to an ambulance for referrals, no transport was available from the community to the healthcare facility.
\end{abstract}

\footnotetext{
*Correspondence: esperanca.sevene@manhica.net; esevene68@gmail.com

${ }^{1}$ Maternal Health Unit, Centro de Investigação em Saúde da Manhiça (CISM), Manhiça, Mozambique

Full list of author information is available at the end of the article Members of the "CLIP Feasibility Working Group" are listed in

acknowledgements section.
}

(c) The Author(s) 2021. Open Access This article is licensed under a Creative Commons Attribution 4.0 International License, which permits use, sharing, adaptation, distribution and reproduction in any medium or format, as long as you give appropriate credit to the original author(s) and the source, provide a link to the Creative Commons licence, and indicate if changes were made. The images or other third party material in this article are included in the article's Creative Commons licence, unless indicated otherwise in a credit line to the material. If material is not included in the article's Creative Commons licence and your intended use is not permitted by statutory regulation or exceeds the permitted use, you will need to obtain permission directly from the copyright holder. To view a copy of this licence, visit http://creativecommons.org/licenses/by/4.0/. The Creative Commons Public Domain Dedication waiver (http://creativeco mmons.org/publicdomain/zero/1.0/) applies to the data made available in this article, unless otherwise stated in a credit line to the data. 
Conclusions: This study showed that task-sharing for screening and pre-referral management of pre-eclampsia and eclampsia were deemed feasible and acceptable at the community-level, but an effort should be in place to address challenges at the health system level.

\section{Plain Language Summary}

Maternal mortality is an important public health problem in Mozambique. Delays in reaching health facilities and insufficient health care professionals call for innovative community-level solutions. We conducted a study to describe the feasibility of task-sharing the screening and initiation of management for pre-eclampsia/eclampsia from the primary healthcare providers to community health workers in Mozambique and to document healthcare facility preparedness to respond to referrals. The study was done to inform a future intervention trial known as the CommunityLevel Interventions for Pre-eclampsia (CLIP) study. We interviewed community health workers, women, various community groups, health care providers, and policymakers and assessed health facilities in Maputo and Gaza provinces, Mozambique. Our results showed that community health workers in Mozambique were trained to identify the basic danger signs of pregnancy; however, they were not trained or equipped to provide obstetric emergencies care prior to referral. Nurses at primary health facilities were supportive of task-sharing with community health workers; however, some barriers mentioned include a lack of equipment, shortage of supervisors, and irregular drug availability. Local stakeholders emphasized the need for comprehensive training and supervision of community health workers to take on new tasks. Task-sharing for screening and pre-referral management of pre-eclampsia and eclampsia was deemed feasible at the community level in southern Mozambique, but still, to be addressed some health system level barriers to the management of pregnancies complications.

Keywords: Task-sharing, Community health workers, Pre-eclampsia, Maternal mortality, Mozambique

\section{Introduction}

Maternal mortality is an important public health problem in low- and middle-income countries (LMICs). Unfortunately, the Millennium Development Goal of reducing maternal mortality rate by three-quarters by 2015 [1] was far from being achieved in most low-income countries, where the rates are 100 times higher than those in highincome countries [2]. Countries need to accelerate their strategies to achieve the target of reducing the global maternal mortality ratio to less than 70 per 100,000 live births by 2030, as planned in the Sustainable Development Goal [3].

In Mozambique, the 2007 demographic census showed a maternal mortality rate of 500/100,000 live births with large differences between the provinces (272-822/100,000 live births) [4]. However, despite many efforts to reduce maternal mortality, it has made little progress at 480/100,000 live births in 2015 [2] and 452/100,000 live births in 2017 [5]. Most maternal deaths in Mozambique result from direct causes such as postpartum haemorrhage, hypertension, eclampsia and puerperal sepsis and pre-eclampsia and eclampsia are the top three causes of maternal death [6-8]. There is robust evidence for magnesium sulphate $\left(\mathrm{MgSO}_{4}\right)$ efficacy in the treatment of eclampsia [9-12]. Many more women could benefit from $\mathrm{MgSO}_{4}$ if appropriate policies were in place. However, the shortage of health professionals often prevents timely detection and management of hypertension in pregnancy [13]. On the other hand, delays in arriving at health facilities due to long distances, poor road conditions, and the absence of regular transport further complicate maternal care [14-16]. Therefore, new and innovative strategies are needed to improve maternal health outcomes across the country. Strategies should start at the communitylevel to reduce these delays and the associated maternal and perinatal complications. These strategies may include a package of evidence-based interventions at the community and primary health care (PHC) to identify and rapidly manage pre-eclampsia/eclampsia (PE/E). Evidence-based interventions should include validated methods to predict adverse pregnancy outcomes to allow prompt referral and the initiation of life-saving treatments [17]. Community health workers (CHWs) may be the appropriate community-level cadre to fulfil this task.

CHWs in Mozambique have increasingly taken on clinical tasks, such as the management of malaria, diarrhoea, pneumonia, severe acute malnutrition and home visits for new-borns $[18,19]$. Recently the World Health Organization (WHO) and the International Federation of Gynaecology and Obstetrics (FIGO) recognized the need to introduce misoprostol at the community level to prevent post-partum haemorrhage [20]. As a result, some low-income countries, including Mozambique, are adapting their programs to include this recommendation with varying levels of success $[18,21,22]$. 
This study aimed to describe the feasibility of task-sharing screening and initiation of emergency management of pre-eclampsia between CHWs and primary healthcare providers in Mozambique and to document facility preparedness to respond.

\section{Methods}

\section{Study design}

The findings hereby reported are part of a broader multicentre study on "The Feasibility of Community-Level Interventions for the prevention and treatment of Preeclampsia and Eclampsia in selected rural communities of southern Mozambique (CLIP Feasibility)" [23]. The feasibility study was implemented in advance of the CLIP trial (NCT01911494), which aimed to assess a community-level intervention for the management of $\mathrm{PE} / \mathrm{E}$. The CLIP trial intervention consisted of community engagement, early identification of danger signs of PE/E, administration of oral methyldopa and intramuscular $\mathrm{MgSO}_{4}$ when needed and referral to the nearest health facility. To detect the signs of PE/E, CHWs were equipped with a mHealth application for guided risk stratification. The proposed CLIP Trial intervention that this study aimed to inform was planned to cover two delays, namely seeking care and prompt referral [24, 25].

The formative research study used a mixed methods (qualitative and quantitative). The qualitative approach was based on focus group discussions with health care providers (maternal and child health nurses, midwives, matrons, and TBAs) and other community members (pregnant women, partners and husbands, mothers and mothers-in-law), in-depth interviews with CHW supervisors, the chief medical officers and gynaecologists and obstetricians' experts. The quantitative data was captured through health facility assessment and community health worker self-administered questionnaires. Data was complemented by a national-level document review of CHWs training curricula, job descriptions, and practice guidelines for the management of pre-eclampsia.

Data collections guides were developed centrally by the study coordination team and adapted from those used in the other countries involved in the study (Nigeria, India and Pakistan). A detailed description of these methods is presented elsewhere [23].

\section{Study area and population}

Mozambique is a low-income country in southern Africa, covering $799,380 \mathrm{Km}^{2}$, with a population of $27,909,798$ in 2017 [5]. The GDP is 646 USD per capita, with around $60 \%$ of the population living under the poverty line [4]. The country is divided into 11 provinces, which are the basis of the health services administration. The National Health Service (NHS) is based on primary health care, with a $50-60 \%$ population coverage rate. The uncovered population live in remote areas with limited access; many of these regions do not have primary health care (PHC). In regions with PHCs, they often do not have adequate human resources, equipment or medicines [26]. In 2019, the total number of medical doctors in the NHS was 2556 (8.7 medical doctors per 100,000 inhabitants), and there were over 6000 maternal and child health nurses (52.6 nurses per 100,000 inhabitants) [27]. To overcome the shortage of medical doctors in the country, nurses and clinical officers have been trained to take on additional duties [28]. In 1978 the country introduced CHWs, designated as Agentes Polivalentes Elementares (APEs). CHW are considered volunteers supported by the Ministry of Health $(\mathrm{MoH})$ although they receive a monthly subsidy equivalent to 20 US dollars (1200 meticais) per month as compensation for their work [29, 30]. These workers are chosen by the community and must have basic literacy and arithmetic skills. They complete intensive fourmonth training. Their responsibilities focus on health promotion and prevention, but in 2010 the MoH revitalized the programme to include some curative activities. Therefore, $\mathrm{CHW}$ tasks are continuously being reviewed and adapted [31]. The curative activities focus on the most prevalent childhood illnesses, including malaria, diarrhoea, acute respiratory tract infection, severe acute malnutrition, and home visits for new-borns. In addition, they may promote attendance for antenatal care, identify danger signs in pregnancy and refer pregnant women as needed. However, there is no specific guideline regarding the diagnosis or management of $\mathrm{PE} / \mathrm{E}$.

Although in Mozambique, APEs are the leading cadre of CHWs, others also provide obstetric care at the community level, namely the matrons and traditional birth attendants (TBA). Matrons and TBAs are knowledgeable elders in their community with vast experience in maternity care. In Mozambique, the shortage of skilled birth attendants and limited coverage of births in facilities resulted in government support of TBAs and matrons in the late 1980s. However, more recently, the Ministry of Health has discouraged deliveries by TBAs as they were seen to challenge facility-based delivery. There were also concerns regarding the risk of HIV infection due to TBAs poor work conditions [32].

This study was conducted in the two southern-most provinces of Mozambique, namely Maputo and Gaza. In Maputo Province, two districts were involved Manhiça and Magude, while in Gaza, four districts were included Chokwé, Xai-Xai, Chibuto and Macia (Fig. 1). The study area has urban and rural areas. Most residents of this region belong to the Changana ethnic group. The predominant occupation is subsistence farming, especially among women. In southern Mozambique, most men 


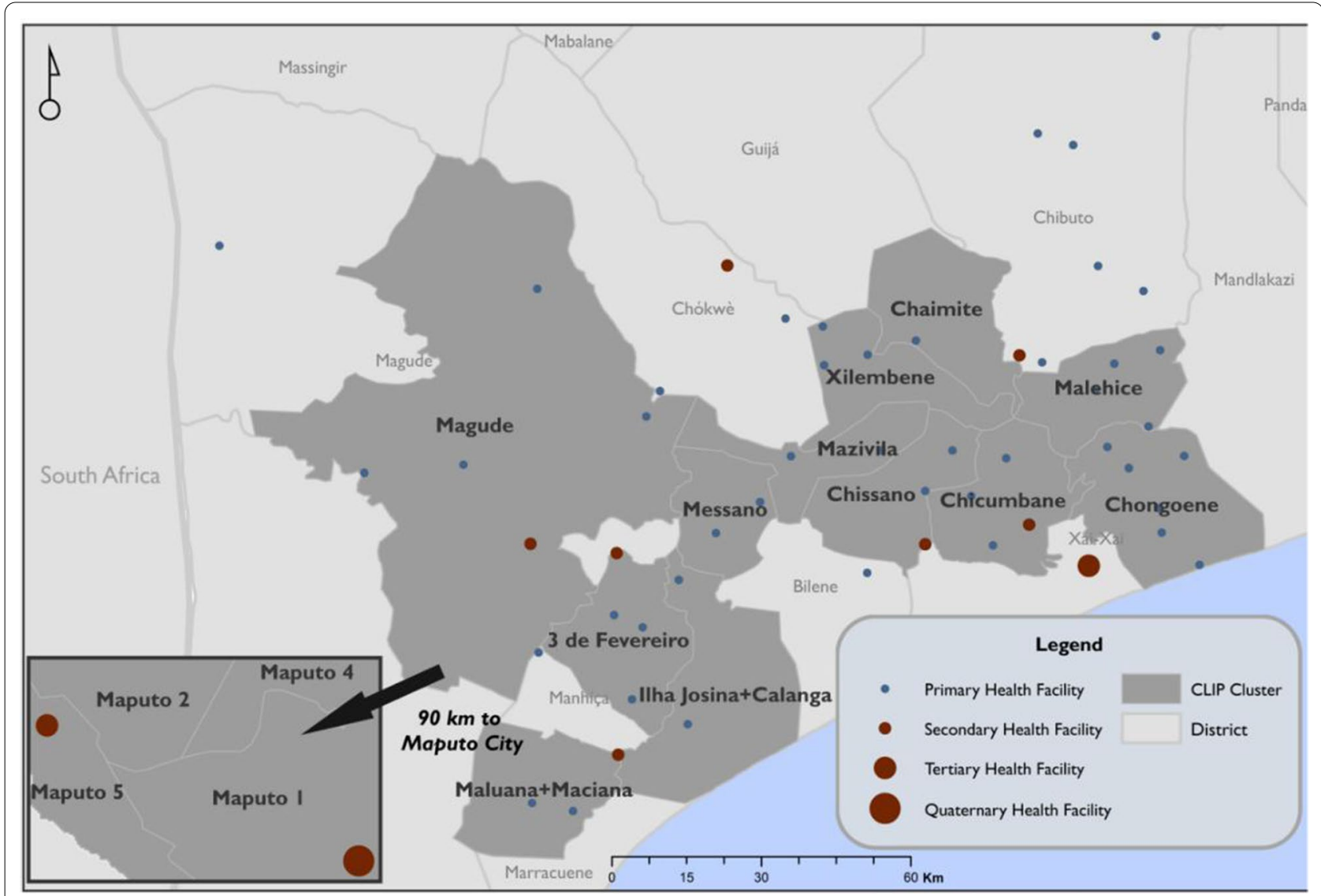

Fig. 1 Map of the study area with representation of the health facilities participating in the study

migrate to South Africa, Swaziland and other cities in Mozambique for work [4]. Literacy rates vary between the two provinces, with a $22 \%$ literacy rate in Maputo and $38 \%$ in Gaza; in both cases, literacy is lowest among women [4]. More details on the study site were described elsewhere [33]. This analysis was complemented by a national-level document review of CHWs curricula, job descriptions, and national practice guidelines for the management of pre-eclampsia [34].

\section{Data collection}

This analysis is the triangulation of five sources: a document review, $\mathrm{CHW}$ self-administered questionnaires, health facility assessments, in-depth interviews, and focus group discussions. Data collection was conducted between September 2013 and May 2014. This process was conducted by a Mozambican team comprising a junior social scientist $(\mathrm{HB})$, clinicians $(\mathrm{AV}, \mathrm{AN})$ and trained interviewers (RP, AM, AT, LM), all employed by the Manhiça Health Research Centre (CISM). The team was supervised by a senior social scientist (KM) and the study principal investigator (ES). Interviewers were selected due to their familiarity with the communities and their research experience. Data collection teams included men and women, fluent in Portuguese and Changana (the predominant local language), and had no prior relationship with participants.

\section{Quantitative data collection Health facility assessment}

The health facility questionnaire collected information about the level of care, available medication and commodities, diagnostic capacity, human resource capacity, obstetric statistics, including patient volume, mode of delivery, morbidity and mortality rates. All (56) health facilities in the study area, based on the list of facilities obtained from the Provincial Directorate for Health, were included in this assessment. The health facility questionnaire was completed by the chief nurse in the maternal and child health care. In primary health centres, only one nurse responded, but at other centres, the chief nurse and the midwife responsible for the maternity ward completed the questionnaire. The health facility clinical chief supported the study team in obtaining access to the necessary individuals for interview. The interviews took $30-45 \mathrm{~min}$ and were completed when the 
nurse's workload was small. The questionnaire comprised of closed-ended questions which were mediated by a trained clinician. Items related to equipment and medications were verified through spot-check observations; only equipment that was physically seen by the study team was considered available.

\section{CHW questionnaire}

The CHW questionnaire assessed CHW preparedness, knowledge and skills to perform home-based treatment for PE/E and the capacity to give intramuscular injections to pregnant women [35]. Most questions used a Likertscale and one open-ended question. All CHWs from the study area were included and were reached through the health facility to which they report according to a list provided by the district CHW program focal person. Data collection was conducted either in the health facility where each CHW was registered or at their home. Depending on the number of CHWs, individual or collective briefing sessions by a study team member were given to explain the questionnaire. Because CHWs had limited literacy, a study team member was present at the interview for clarification. The questionnaire took 30-45 min.

\section{Qualitative data collection In-depth interviews}

The interviews focused on the experience of $\mathrm{CHW}$ program coordinators regarding $\mathrm{CHW}$ requirements, roles and responsibilities, including in the management of pregnant complications. The Mozambican Gynaecologists and Obstetricians Association (AMOG) identified individuals for interview based on their experience and contribution to relevant maternal health policies. At the district level, the chief medical officers and the $\mathrm{CHW}$ supervisors were interviewed. The interviews were conducted by trained social scientists. Each interview lasted 30-45 min, was audio-recorded, and notes were taken; they were conducted one-on-one in the house or workplace of participants, depending on their preference.

\section{Focus group discussions}

The focus group discussion (FGD) guide touched upon the following topics: views on pregnancy complications, pregnancy management, preventive and treatment practices and the health workers' role in managing pregnancy complications. Focus groups were chosen to best capture views of maternal and child health nurses, midwives, matrons and traditional birth attendants, and other community members (pregnant women, partners and husbands, mothers and mothers-in-law). FGDs with nurses and midwives were conducted at health facilities, as these groups could easily be convened and were scheduled at times when health care providers were less busy.
For matrons and traditional birth attendants, the FDGs were in Changana (local language) and took place at the community, either at the círculos (the usual community gathering location) or at the community leaders' house, according to the groups' convenience. The FGDs were conducted by trained social scientists. Each FGD lasted between 30 and $80 \mathrm{~min}$, was audio-recorded and notes were also taken.

Panel discussions were also held at the Ministry of Health (with the Deputy Director of Public Health and his team), Maputo Provincial Directorate (with Provincial Medical Chief and his team) and in Manhiça (with members of Community Advisor Committee and with members of CISM Institutional Ethics Review Board). This exercise obtained views regarding task-sharing and was used to understand the policies and the processes related to $\mathrm{CHWs}$.

\section{Data management and analysis}

Information obtained through the desk review was summarized to extract relevant information regarding the history, role and challenges facing $\mathrm{CHWs}$ providing maternal and child health care.

The data captured were sent to CISM Data Centre for double data entry and management using REDCap [36]. Prior to sending data to the CISM Data Centre, the study team reviewed each questionnaire in the field. The failures to validation rules and double data entry discrepancies were cross-checked with paper forms for confirmation. Frequency and cross tables were employed for data consistency checks. Outliers and missing values were also reviewed. Data were exported to Stata 13 (Stata Corp., College Station, Texas, USA) for analysis. Frequencies, means, medians, SD and IQR, were used to describe the data.

Focus group discussions and in-depth interviews were digitally recorded using Olympus AS-2400 $\mathrm{PC}^{\circledR}$ recorders. In addition, FGDs, IDIs and the open-ended question from the $\mathrm{CHW}$ questionnaire were transcribed verbatim by the same team members who completed data collection. In-depth interviews and the $\mathrm{CHW}$ questionnaire were collected and transcribed in Portuguese, while focus group discussions were translated to Portuguese from the local language as needed while being transcribed. Quality control of transcripts was ensured by listening to $25 \%$ of the audio recordings and comparing them against the transcripts for accuracy and completeness. The qualitative data were analysed using NVivo version 10.0 (QSR International Pty. Ltd. 2012). A thematic analysis approach was taken (see Fig. 2). The coding structure (based on free nodes, branched nodes, attributes and some pre-determined queries) was developed in advance based on study objectives through a collaborative 


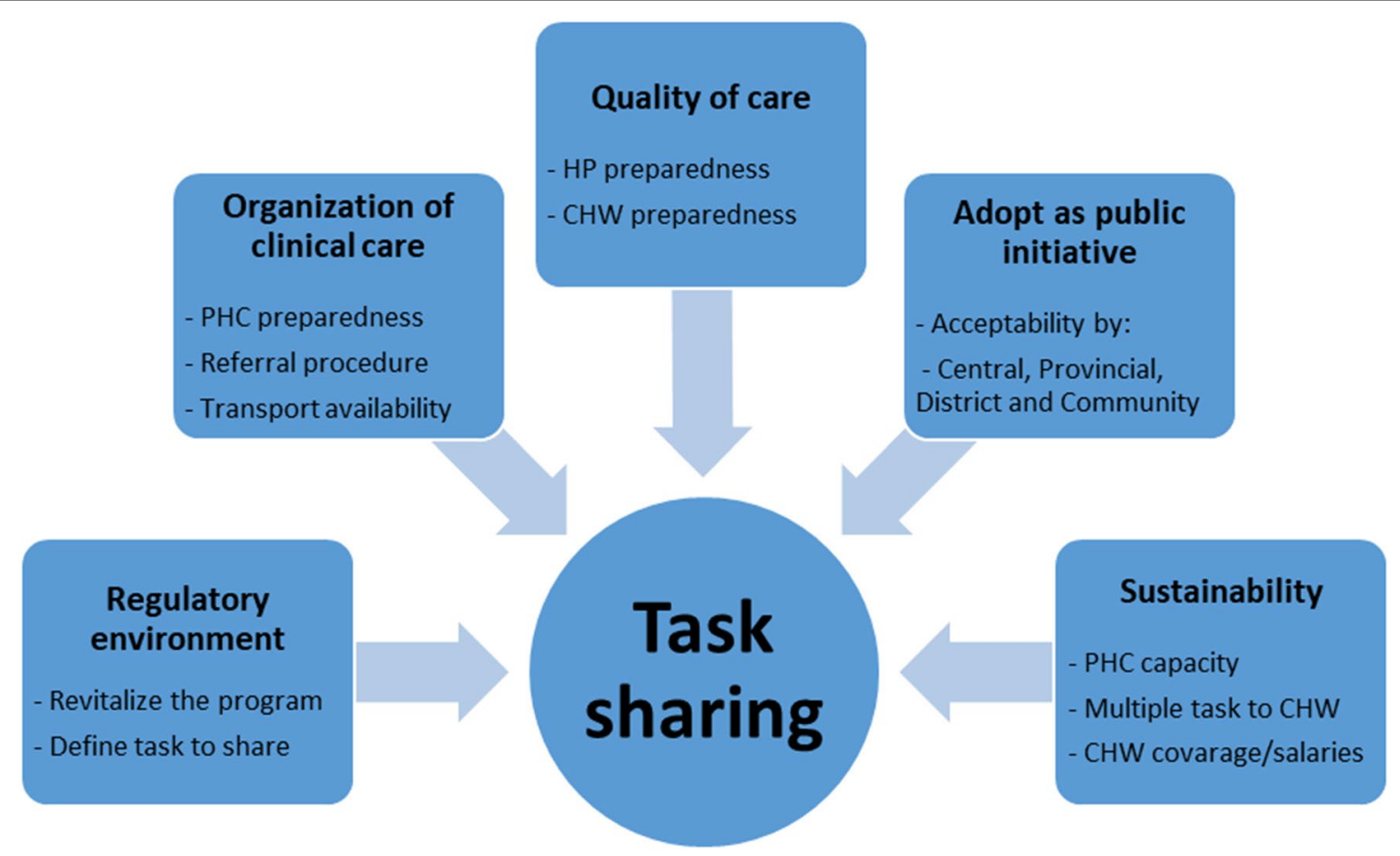

Fig. 2 Analysis scheme

discussion between researchers at CISM and the University of British Columbia (UBC). Themes were subsequently adjusted, and new themes added as they emerged from the data. As the analysis was performed by two teams (CISM and UBC), the coding structured was in English. The two Mozambican social scientists coded all transcriptions in Portuguese by reading the text in Portuguese and labelling the concepts using the codes in English. Three IDI and two FGD transcripts were translated from Portuguese to English and coded by a social scientist based at UBC for three purposes: first, to support the discussions on the development of the coding structure; second, for the UBC collaborator to be familiar with the raw data, to assist interpretation; and finally, for quality control. To allow the two teams to work independently, the data was split into two NVivo projects, but the same coding structure was used for both teams. Regular coding consensus meetings to discuss data analysis strategy and findings were held via Skype ${ }^{\mathrm{TM}}$. The coding agreement between the coders was very high. When the coding was completed, the analysed data were merged into a single project managed by the Mozambican team, from which the final queries, interpretation and data reduction were conducted.

To define our study constructs, we used the 2007 WHO task-sharing global recommendation and guidelines. In this document, we found five essential recommendations to guide task-sharing: adoption as a public health initiative, enabling regulatory environment, ensuring the quality of care, ensuring organization of the clinical care service and ensuring the sustainability [37].

\section{Ethical considerations}

This study received approval from the CISM Institutional Review Board (CIBS_CISM/08/2013) and the University of British Columbia in Canada (H12-00132). All participants in the study provided informed consent after receiving a written study information sheet and a detailed verbal explanation. For the illiterate participants, a literate witness was asked to read and explain to the participant the contents of the participant information sheet. The consent form was signed by the witness, and the researcher assistant after the participant's fingerprint was taken. All identifiable data of participants were anonymised through attribution of unique identification numbers or pseudonyms to guarantee anonymity. Before the field activities, the first contact was made with the Ministry of Health, the Provincial and District Health Directorate to obtain permission for data collection.

\section{Results}

Organization of clinical care

The health facility assessment questionnaire was completed by 56 chief nurses and 10 midwives. Fifty-six 
(56) health facilities were assessed: one quaternary, two tertiary, seven secondary and 46 primary health centres (see Fig. 1). All health facilities assessed were public, managed by the Ministry of Health and offer ANC and delivery services. The entry point to the health system was the PHC, and it was recommended that CHWs refer to this level. All facilities reported at least one type of blood pressure machine (digital or manual) to screen for hypertension and pre-eclampsia. Albumin urine tests (proteinuria) were not available at the primary level and in more than half (57\%) of secondary facilities (see Table 1).

Methyldopa was available in most primary $(76 \%)$ and secondary (86\%) level health facilities. The interviewees said that the availability of antihypertensives depends on what they receive from the central drug store. Even though the guideline recommends hydralazine, methyldopa or nifedipine, prescribing practice reflect availability. $\mathrm{MgSO}_{4}$ was available in most primary $(83 \%)$ and all secondary (100\%) level facilities, although stockouts had

Table 1 Participants demographic information

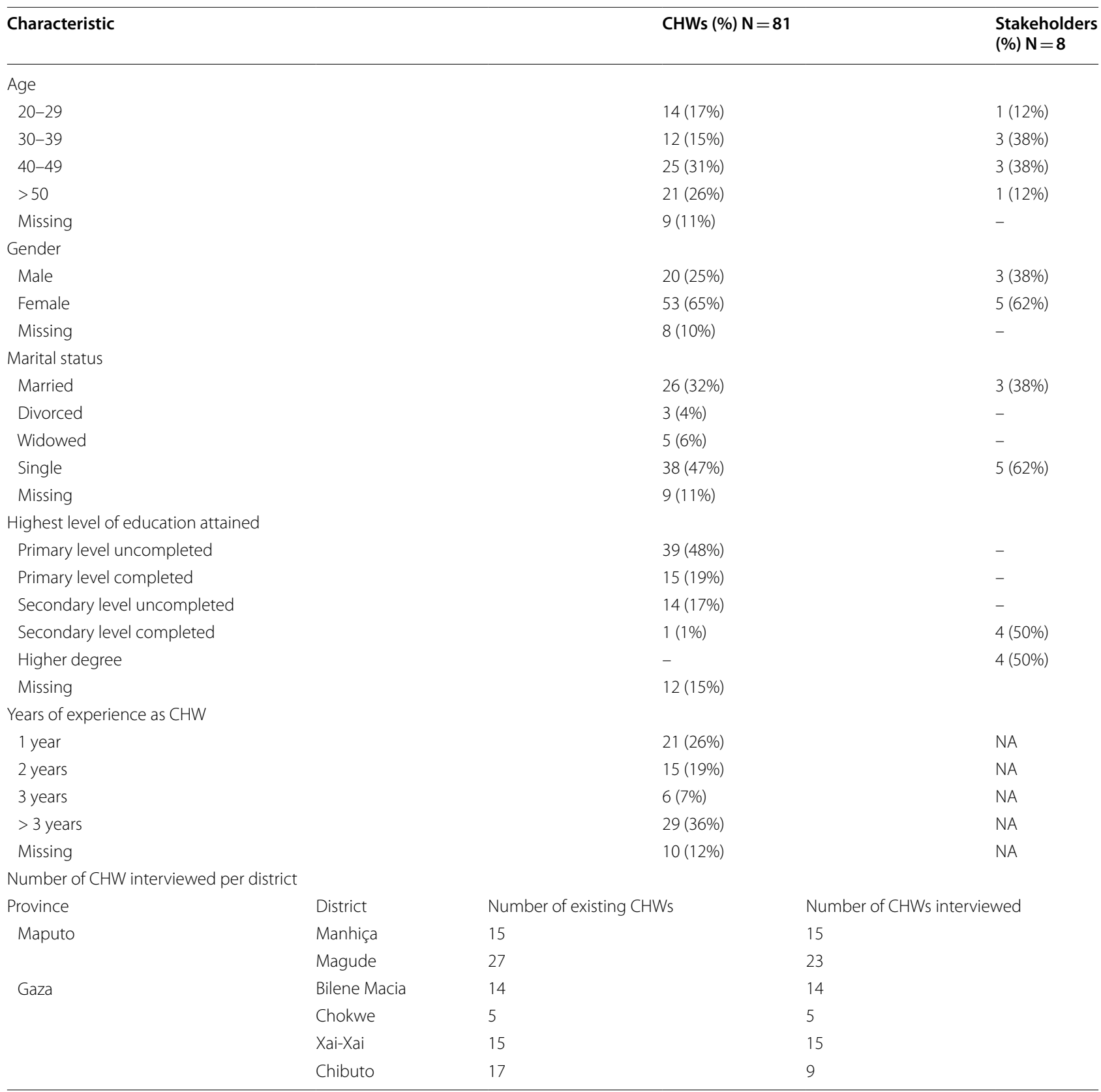


been reported in one primary, two tertiary and one quaternary facility (see Table 1 ).

\section{Quality of care assurance Health facility-based professionals' preparedness}

At the primary level, only one to two nurses with basic (grade $7+3$ years of nurse training) or moderate training (grade $10+2$ years of nurse training) were responsible for maternity health, and the numbers of providers remain low in higher levels of care. Midwives were called maternal and child health nurses (MCHN) (enfermeiras de saúde materno-infantil), and they were all full-time employees in health facilities. These nurses were responsible for all obstetric care at the primary and secondary level. Some MCHN were trained to perform caesarean sections (see Table 1). Obstetricians were only found in tertiary and quaternary facilities.

All nurses reported awareness of $\mathrm{PE} / \mathrm{E}$ and had been trained to identify the danger signs of pregnancy, including those related to $\mathrm{PE} / \mathrm{E}$. The diagnosis of $\mathrm{PE} / \mathrm{E}$ was based on symptoms and the measurement of blood pressure without assessing proteinuria. They are trained to administer $\mathrm{MgSO}_{4}$ before referral to the nearest higherlevel facility. There is an obstetric care guidebook with a chapter on diagnoses and management of $\mathrm{PE} / \mathrm{E}$ and a flowchart of procedures and algorithms in case of $\mathrm{PE} / \mathrm{E}$ including drugs to be administered and dosages. This guidebook and flowchart were available in all delivery rooms.

For the treatment of women with pre-eclampsia, the nurses mentioned having methyldopa and hydralazine. In the case of convulsions, nurses reported using magnesium sulphate intravenously before referral.

I... medications that I have to treat complications... I just have serums, and I have magnesium sulphate, methyldopa, and I have hydralazine. These are the medications that I have here. I usually give methyldopa and hydralazine when a woman has severe pre-eclampsia. $\mathbf{M C H}$ nurses

Uh... [Laughs] Magnesium sulphate ... which we usually give when you have convulsions, we just suddenly take a bottle and give (give) it directly into the vein. $\mathbf{M C H}$ nurses

\section{Community health workers' preparedness}

For this study, $81 \mathrm{CHWs}$ were identified, representing $87 \%$ of all CHWs in the study area. The CHWs were from Manhiça (15), Magude (23), Bilene Macia (14), Chokwe (5), Xai-Xai (15) and Chibuto (9) (see Table 2). In Maputo, four CHWs, all from Magude District, were not included because they lived very far from the health facility where data collection occurred or were not reachable at the time of study recruitment. In Gaza, eight CHWs, all from Malehice and Chibuto District, were not included as data collection took place during and immediately after flooding and access to and communications with the health units was not possible. IDIs were also done with three CHW supervisors, three District Chief Medical Officers, and two obstetrician-gynaecologists from AMOG. A total of 26 FGDs were conducted with pregnant women (5), partners and husbands (5), mothers and mothers-inlaw (5), matrons and TBAs (5), community leaders (1) and health workers (5). The panel discussion was with four IRB members (1), Community Advisory Board (1), Ministry of Health (1) and Provincial Directorate (1) (see Tables 2 and 3).

CHWs do regular home visits for pregnant women. During these visits, they provide health education about the importance of ANC and facility delivery, and check the ANC record to confirm the pregnant women was attending the scheduled visits. Their visits also include identifying of warning signs in pregnancy: anaemia, oedema, vaginal bleeding, and abdominal pain. According to our questionnaire, most CHWs (94\%) agreed that they knew the warning signs of pregnancy, although fewer were familiar with the warning signs of hypertension in pregnancy $(41 \%)$; despite this, most report recognition of convulsions (70\%). The CHWs were not trained nor equipped to detect hypertension and proteinuria. In line with these findings, few were comfortable providing oral medications $(47 \%)$ or injections $(5 \%)$ of any kind to pregnant women. The management of specific complications in pregnancy, such as pre-eclampsia and eclampsia, is not part of CHWs' regular tasks.

According to supervisors, CHWs are skilled to identify the basic danger signs of pregnancy, but they could not manage these emergencies; instead, they refer.

The CHWs are not trained to identify hypertension in pregnancy. In cases of eclampsia, they immediately refer the pregnant women. As they are not trained nor equipped to manage these situations, one can assume that they do not have an in-depth understanding of the condition and its complexities. CHW supervisor

Matrons and TBAs also attend pregnant women at the community level, but they are discouraged by the health system from assisting deliveries at home.

"There was [childbirth in the community], but it emerged that they could no longer give birth at home, midwives can no longer work, they [pregnant women] must go to the hospital, and if the hospital is far away, they have to go first and stay at a maternity waiting home. We helped [the pregnant women], 
Table 2 Characteristics of focus group discussion participants

\begin{tabular}{|c|c|c|c|c|c|c|c|}
\hline$\#$ & Stakeholder Group & Region & \# of Participants & Age (Median) & Marital status & Occupation & Schooling level \\
\hline 1 & \multirow[t]{5}{*}{$\begin{array}{l}\text { Women of reproduc- } \\
\text { tive age }\end{array}$} & Ilha Josina Machel & 9 & 30 & Married (9) & Farmer (9) & $\begin{array}{l}\text { Never studied (3) } \\
\text { Primary (6) }\end{array}$ \\
\hline 2 & & Calanga & 3 & 25 & Married (3) & Farmer (3) & Primary (3) \\
\hline 3 & & Três de Fevereiro & 8 & 23 & Married (8) & Farmer (8) & $\begin{array}{l}\text { Never studied (1) } \\
\text { Primary (4) } \\
\text { Secondary (3) }\end{array}$ \\
\hline 4 & & Messano & 8 & 28 & $\begin{array}{l}\text { Married (6) } \\
\text { Widow (1) } \\
\text { Single (1) }\end{array}$ & $\begin{array}{l}\text { Farmer (7) } \\
\text { Nurse (1) }\end{array}$ & $\begin{array}{l}\text { Primary (7) } \\
\text { Secondary (1) }\end{array}$ \\
\hline 5 & & Chongoene & Unknown* & Unknown & Unknown & Unknown & Unknown \\
\hline 6 & \multirow[t]{5}{*}{$\begin{array}{l}\text { Mothers and mothers- } \\
\text { in-law }\end{array}$} & Ilha Josina Machel & 12 & 29 & $\begin{array}{l}\text { Married (7) } \\
\text { Widow (5) }\end{array}$ & Farmer (12) & $\begin{array}{l}\text { Never studied (4) } \\
\text { Primary (8) }\end{array}$ \\
\hline 7 & & Calanga & 12 & 59 & $\begin{array}{l}\text { Married (7) } \\
\text { Widow (3) } \\
\text { Divorced (2) }\end{array}$ & Farmer (12) & $\begin{array}{l}\text { Never studied (1) } \\
\text { Primary (11) }\end{array}$ \\
\hline 8 & & Três de Fevereiro & Unknown & Unknown & Unknown & Unknown & Unknown \\
\hline 9 & & Messano & 8 & 39 & $\begin{array}{l}\text { Married (5) } \\
\text { Widow (1) } \\
\text { Single (2) }\end{array}$ & Farmer (8) & $\begin{array}{l}\text { Never studied (6) } \\
\text { Primary (2) }\end{array}$ \\
\hline 10 & & Chongoene & 11 & 46 & $\begin{array}{l}\text { Married (3) } \\
\text { Widow (1) } \\
\text { Single (7) }\end{array}$ & Housewife (11) & $\begin{array}{l}\text { Never studied (3) } \\
\text { Primary (8) }\end{array}$ \\
\hline 11 & \multirow[t]{5}{*}{ Partners and husbands } & Ilha Josina Machel & 12 & 37 & Married (12) & Farmer (12) & $\begin{array}{l}\text { Never studied (3) } \\
\text { Primary (8) } \\
\text { Secondary (1) }\end{array}$ \\
\hline 12 & & Calanga & 4 & 37 & Married (4) & $\begin{array}{l}\text { Farmer (1) } \\
\text { Fisherman (1) } \\
\text { Traditional healer (1) } \\
\text { Locality chief (1) }\end{array}$ & $\begin{array}{l}\text { Never studied (1) } \\
\text { Primary (3) }\end{array}$ \\
\hline 13 & & Três de Fevereiro & 10 & 45 & Married (10) & $\begin{array}{l}\text { Farmer (3) } \\
\text { Security (2) } \\
\text { Seller (1) } \\
\text { Mason (1) } \\
\text { Small jobs (2) } \\
\text { Gas station clerck (1) }\end{array}$ & Primary (10) \\
\hline 14 & & Messano & 6 & 42 & Married (6) & Farmer (6) & Primary (6) \\
\hline 15 & & Chongoene & 7 & 49 & $\begin{array}{l}\text { Married (3) } \\
\text { Single (4) }\end{array}$ & $\begin{array}{l}\text { Farmer 6) } \\
\text { Driver (1) }\end{array}$ & Primary (7) \\
\hline 16 & \multirow{5}{*}{$\begin{array}{l}\text { Matrons and tradi- } \\
\text { tional birth attend- } \\
\text { ants }\end{array}$} & Ilha Josina Machel & 6 & 55 & $\begin{array}{l}\text { Married (3) } \\
\text { Widow (3) }\end{array}$ & Farmer (6) & $\begin{array}{l}\text { Never studied (5) } \\
\text { Primary (1) }\end{array}$ \\
\hline 17 & & Calanga & 9 & 67 & $\begin{array}{l}\text { Married (3) } \\
\text { Widow (4) } \\
\text { Divorced (2) }\end{array}$ & Farmer (9) & Primary (9) \\
\hline 18 & & Três de Fevereiro & 12 & 65 & $\begin{array}{l}\text { Married (4) } \\
\text { Widow (7) } \\
\text { Divorced (1) }\end{array}$ & Farmer (12) & $\begin{array}{l}\text { Never studied (9) } \\
\text { Primary (3) }\end{array}$ \\
\hline 19 & & Messano & 10 & 43 & $\begin{array}{l}\text { Married (5) } \\
\text { Widow (3) } \\
\text { Single (2) }\end{array}$ & $\begin{array}{l}\text { Farmer (8) } \\
\text { Teacher (1) } \\
\text { Housewife (1) }\end{array}$ & $\begin{array}{l}\text { Never studied (1) } \\
\text { Primary (7) } \\
\text { Secondary (2) }\end{array}$ \\
\hline 20 & & Chongoene & 9 & 58 & $\begin{array}{l}\text { Married (2) } \\
\text { Widow (1) } \\
\text { Single (6) }\end{array}$ & Housewife (9) & $\begin{array}{l}\text { Never studied (7) } \\
\text { Primary (2) }\end{array}$ \\
\hline
\end{tabular}


Table 2 (continued)

\begin{tabular}{|c|c|c|c|c|c|c|c|}
\hline$\#$ & Stakeholder Group & Region & \# of Participants & Age (Median) & Marital status & Occupation & Schooling level \\
\hline 21 & Health professionals & Ilha Josina Machel & 4 & 28 & Married (4) & $\begin{array}{l}\text { Health technician (1) } \\
\text { Health agent (3) }\end{array}$ & $\begin{array}{l}\text { Primary (1) } \\
\text { Secondary (3) }\end{array}$ \\
\hline 22 & & Calanga & Unknown & Unknown & Unknown & Unknown & Unknown \\
\hline 23 & & Três de Fevereiro & 2 & 51 & Married (2) & $\begin{array}{l}\text { Midwife (1) Health techni- } \\
\text { cian (1) }\end{array}$ & Secondary (2) \\
\hline 24 & & Messano & 3 & 26 & $\begin{array}{l}\text { Married (2) } \\
\text { Single (1) }\end{array}$ & $\begin{array}{l}\text { Nurses (2) } \\
\text { Counsellor (1) }\end{array}$ & Secondary (3) \\
\hline 25 & & Chongoene & 2 & 30 & Single (2) & Nurse (1) Assistant (1) & Secondary (2) \\
\hline \multicolumn{8}{|c|}{ Panel discussion } \\
\hline 1 & $\begin{array}{l}\text { Community Advisor } \\
\text { Board }\end{array}$ & Manhiça & 6 & 57 & $\begin{array}{l}\text { Married (4) } \\
\text { Widow (1) } \\
\text { Divorced (1) }\end{array}$ & $\begin{array}{l}\text { community leader and } \\
\text { neighborhood chief (4) } \\
\text { Traditional healer (1) } \\
\text { Activist (1) }\end{array}$ & Primary (6) \\
\hline 2 & IRB & Manhiça & 6 & 39 & $\begin{array}{l}\text { Married (3) } \\
\text { Single (3) }\end{array}$ & $\begin{array}{l}\text { Medical doctor (2) } \\
\text { Teacher (1) } \\
\text { Judge (1) } \\
\text { Theologian (1) } \\
\text { Community Liaison } \\
\text { Officer (1) }\end{array}$ & $\begin{array}{l}\text { Licenciature (5) } \\
\text { Secondary (1) }\end{array}$ \\
\hline
\end{tabular}

${ }^{*}$ Missing data

Table 3 Health facility assessment on available resources for diagnose and manage PE/E

\begin{tabular}{|c|c|c|c|c|c|c|c|c|c|c|}
\hline \multirow[t]{2}{*}{ Type of facility surveyed } & \multicolumn{2}{|c|}{ Primary } & \multicolumn{2}{|c|}{ Secondary } & \multicolumn{2}{|c|}{ Tertiary } & \multicolumn{2}{|c|}{ Quaternary } & \multicolumn{2}{|c|}{ Total } \\
\hline & $\mathbf{N}$ & $\%$ & $\mathbf{N}$ & $\%$ & $\mathbf{N}$ & $\%$ & $\mathbf{N}$ & $\%$ & $\mathrm{~N}$ & $\%$ \\
\hline Total & 46 & & 7 & & 2 & & 1 & & 56 & \\
\hline \multicolumn{11}{|l|}{ Equipment for PE/E diagnose } \\
\hline Digital sphygmomanometer & 30 & $65 \%$ & 2 & $29 \%$ & 0 & $0 \%$ & 0 & $0 \%$ & 32 & $57 \%$ \\
\hline Manual sphygmomanometer & 16 & $35 \%$ & 6 & $86 \%$ & 2 & $100 \%$ & 1 & $100 \%$ & 25 & $45 \%$ \\
\hline Pulse oximeter & 0 & $0 \%$ & 0 & $0 \%$ & 0 & $0 \%$ & 1 & $100 \%$ & 1 & $2 \%$ \\
\hline \multicolumn{11}{|l|}{ Basic diagnostic test } \\
\hline Dipstick proteinuria & 0 & $0 \%$ & 2 & $29 \%$ & 2 & $100 \%$ & 1 & $100 \%$ & 5 & $9 \%$ \\
\hline \multicolumn{11}{|l|}{ Medications for PE/E } \\
\hline Methyldopa PO & 35 & $76 \%$ & 6 & $86 \%$ & 2 & $100 \%$ & 1 & $100 \%$ & 44 & $79 \%$ \\
\hline $\mathrm{MgSO}_{4}$ & 38 & $83 \%$ & 7 & $100 \%$ & 2 & $100 \%$ & 1 & $100 \%$ & 48 & $86 \%$ \\
\hline \multicolumn{11}{|l|}{ Referral transportation } \\
\hline Has a functional ambulance or other vehicle for emergency & 2 & $4 \%$ & 7 & $100 \%$ & 2 & $100 \%$ & 1 & $100 \%$ & 12 & $21 \%$ \\
\hline Has transportation for patients referred to another facility & 43 & $93 \%$ & 7 & $100 \%$ & 2 & $100 \%$ & 1 & $100 \%$ & 53 & $95 \%$ \\
\hline $\begin{array}{l}\text { Has access to an ambulance or other vehicle for emergency } \\
\text { transportation to another facility or that operates from another } \\
\text { facility }\end{array}$ & 44 & $96 \%$ & 7 & $100 \%$ & 2 & $100 \%$ & 1 & $100 \%$ & 54 & $96 \%$ \\
\hline \multicolumn{11}{|l|}{ Health professionals, median (IQR) } \\
\hline Obstetricians & 0 & $(0-0)$ & 0 & $(0-0)$ & 5 & $(1-5)$ & N/A & $\mathrm{N} / \mathrm{A}$ & 5 & $(1-5)$ \\
\hline Nurse & 1 & $(1-2)$ & 5 & $(5-8)$ & 24 & $(17-30)$ & N/A & $\mathrm{N} / \mathrm{A}$ & 5 & $(1-4)$ \\
\hline
\end{tabular}

but there was a time when they said not to give birth at home, you have to give birth at the facility lat the hospital]". Matron

"Yes, we help [women] giving birth, but with the arrival of the hospital, we were forbidden [by the Ministry of Health]. [Women] should go to the hos- pital. It is not because we cannot do [the] birth. We cannot do it; our time ended up. And now we cannot get involved in these new things [new rules]. Our daughters are brought to the hospital now". TBA

According to focus group participants, matrons provide advice to women throughout pregnancy, particularly 
related to traditional practices. The matrons do not formally offer health services, but when there is an emergency in the community, they might be called upon for assistance.

"We have no work; if they give us work, we will do [...]. This order (to visit pregnant women in the houses) we have not had yet but if they give us the order we will visit [...]."-Matron

\section{Acceptability of pre-eclampsia identification and emergency management by CHWs}

During the panel discussions, stakeholders from the $\mathrm{MoH}$ were favourable to task-sharing to $\mathrm{CHWs}$, and they were involved in efforts to revitalize the $\mathrm{CHW}$ programme. However, participants from provincial directorate raised concerns regarding the complexity of curative care on top of the already burdened CHWs. In addition, some were concerned that families would not accept a male CHW to visit a pregnant woman at home.

Obstetrician-gynaecologists were supportive of involving CHWs in community-based interventions in pregnancy; they believed that such interventions would further support maternal and child health nurses. However, they were sceptical of giving CHWs the responsibility of $\mathrm{PE} / \mathrm{E}$ management, especially regarding the administration of intramuscular $\mathrm{MgSO}_{4}$ and the management of potential adverse reactions. They considered only obstetricians-gynaecologists as suitable to evaluate the feasibility or endorse policy related to pregnant women.

"I want to be in peace with myself and my conscience after recommending something which I know will be good for the patients. If I recommend something that I know will bring problems, I will not feel comfortable". Obstetrician-Gynaecologist

District medical officers supported CHW involvement, especially identifying and referral of early-stage preeclampsia to avoid severe disease, including eclampsia. However, they were concerned regarding CHWs ability to manage cases in the community and were not supportive of the administration of injectables by CHWs.

The CHW supervisors did not raise major concerns regarding the involvement of CHWs in the management and referral of PE/E. Caring for pregnant women at the community level would not constitute a major change in their routine. However, the supervisors were not confident that, they would diagnose and treat pre-eclampsia or eclampsia, with their current training. In their view, CHWs would only recognise warning signs in general and not specific to PE/E and quickly refer.
Nurses were favourable to the introduction of community management of pre-eclampsia by CHWs. They, however, highlighted the need first to address current barriers to care of pregnant women at health facilities, including lack of equipment, shortage of supervisors, and irregular drug availability.

The CISM IRB members were favourable of CHWs visiting pregnant women at home and administering oral medication but had reservations regarding injectable medication administration, considering that $\mathrm{CHWs}$ could not monitor adverse events following injections. Furthermore, the Community Advisory Board was supportive as long as it is approved by the government and local leaders.

The CHWs were supportive of the community management of pre-eclampsia and felt that they could take this on with appropriate training. However, they complained about the lack of transport from the community to the health facility, which could affect their ability to refer.

Community members described how this shift in practice would bring CHWs closer to the community and help decrease the problem of PE/E.

\section{"Yes, we would accept (CHWs) just knowing that this is a person from the hospital... We could go to his house even he could come to our houses we would accept because he helps us.- Pregnant women, Manhiça district}

When husbands/partners were asked if they were willing to accept a male CHW to assist pregnant women, they were generally supportive. Therefore, the aim is to provide care to women, similar to their acceptance of male doctors at the health facility.

"For me, in my opinion, it would be possible to attend [attend pregnant women by male CHW], I would be calm because [even myself] when I go to the hospital I do not expect only to be attended by male staff, a nurse can also attend me. However, that person was positioned by health services to heal both people [...] we just know that is a doctor."-Partners and husbands, Messano District

\section{Sustainability}

Although respondents were supportive of the task-sharing, some important challenges were raised. For example, nurses highlighted the need to create capacity at primary health facilities before task-sharing to CHWs, including improving the availability of proteinuria tests and drugs for $\mathrm{PE} / \mathrm{E}$ management. On the other hand, ministry of health and provincial directorate representatives raised concerns of the multiple tasks for which CHWs are responsible without adequate training. The low number 
of CHWs and the low subsidies paid was also a constraint to task-sharing (see Table 4). These concerns should be addressed to ensure the long-term sustainability of such a policy.

\section{Discussion}

This study shows availability of $\mathrm{MgSO}_{4}$ in almost all facilities; this represents an improvement from previous reports in Mozambique, where most facilities did not have $\mathrm{MgSO}_{4}$, and the nurses reported low confidence in its administration [38]. However, $\mathrm{MgSO}_{4}$ is still not available in $17 \%$ of the primary level facilities, like in many African countries; therefore, many women are not receiving this life-saving drug [39]. In addition, the measurement of proteinuria was not part of regular clinical assessment at the primary level and was unavailable in most secondary level facilities [40].

Strengthening the health system with the provision of the necessary equipment and medication for the prevention and treatment of $\mathrm{PE} / \mathrm{E}$ is key to reducing of maternal mortality and facilitating task-sharing between nurses and CHWs. The need for health system strengthening has also been reported for other maternal intervention such as the prevention of neonatal sepsis [41].

Nurses reported having been trained and equipped to measure blood pressure, identify the danger signs of pregnancy, use $\mathrm{MgSO}_{4}$ pre-referral, and contact an ambulance to transport critical patients. However, shortage of health professionals and distance to health facilities were described as challenges for obstetric care where task-sharing with CHWs has been proposed. Although nurses reported being trained and equipped to manage $\mathrm{PE} / \mathrm{E}$, most primary level facilities only have one or two nurses dedicated to maternal care. This aligns with the minimal availability of trained and qualified health workers, with an average of 0.087 physicians and 0.526 nurses and midwives per 1000 population in the country, far short of the WHO recommendation of one nurse and one doctor/1000 population [27]. A study that aimed to evaluate the magnitude of the health facility-based maternal mortality and assessed the health facility factors implicated in these deaths was conducted in 2008 in Mozambique. This study showed that the risk of maternal death was reduced by $40 \%$ in health facilities with nurses trained in maternal and child health and able to provide emergency obstetric care (EmOC). The study has proven the high impact of the mid-level skilled maternal and child health nurses on reducing maternal mortality [42]. There is a need to improve the availability of skilled professionals to ensure the quality of care.

In this study, nurses complained that there were barriers to providing health care at health facilities, which included the lack of equipment, lack of supervision and the irregular availability of medicines. This finding was also found in a recent study that reported that the availability of sexual and reproductive health commodities in health facilities was low in Kenya, Tanzania, Uganda and Zambia [43]. These barriers must be resolved before tasksharing efforts will be successful.

To mitigate the shortfall in the number of health professional, Mozambique adopted a CHW program strategy to improve access to care. In addition, the revitalization of the program has been an opportunity to introduce new community-level interventions. This study also reported that the CHW were confident to include additional tasks in their duties. They were well respected and accepted by their communities which can contribute to improved adherence to new interventions. The district medical officers and $\mathrm{CHW}$ supervisors complained about the low level of training, the low number of $\mathrm{CHW}$ available in the study area and their low subsidies. These results are similar to other studies in Mozambique reporting that apart from their low level of education and training, the limited number of CHWs, the lack of supervision, and their low subsidies are challenges to task-sharing with this cadre [44-47].

Training on the detection of danger sign in pregnancy could facilitate the identification of pre-eclampsia and eclampsia by CHWs; however, the provision of an injectable $\left(\mathrm{MgSO}_{4}\right)$ medication was a barrier to the management of pre-eclampsia by CHWs as it is not part of their regular training. As a result, medical officers and specialists believe that the CHWs are not prepared to identify and manage pregnancy complications with injectable $\mathrm{MgSO}_{4}$.

A previous study in Mozambique showed that Ninetythree percent of CHW had an awareness of pregnancy complications. In cases of eclampsia, CHWs reported referring the women immediately. However, the vast majority of the CHWs surveyed said they could neither measure blood pressure nor proteinuria (90\%). In addition, fewer reported confidence in providing oral antihypertensives $(14 \%)$ or injections in pregnancy $(5 \%)$ [35]. These results illustrate the limited knowledge of the community providers in Mozambique and the need for enhanced regular training. Increasing evidence suggests that CHWs can provide additional services after adequate training, including prevention of post-partum haemorrhage with misoprostol $[48,49]$ and injectable contraception with Depo-Provera [50, 51]. Involvement of the District medical officers and OBGYNs in CHWs task-sharing initiatives, including identifying $\mathrm{PE} / \mathrm{E}$ cases and managing with $\mathrm{MgSO}_{4}$ before referral, could increase the intervention uptake. However, studies to assess the CHW's ability to administer $\mathrm{PE} / \mathrm{E}$ interventions are needed before task-sharing. 


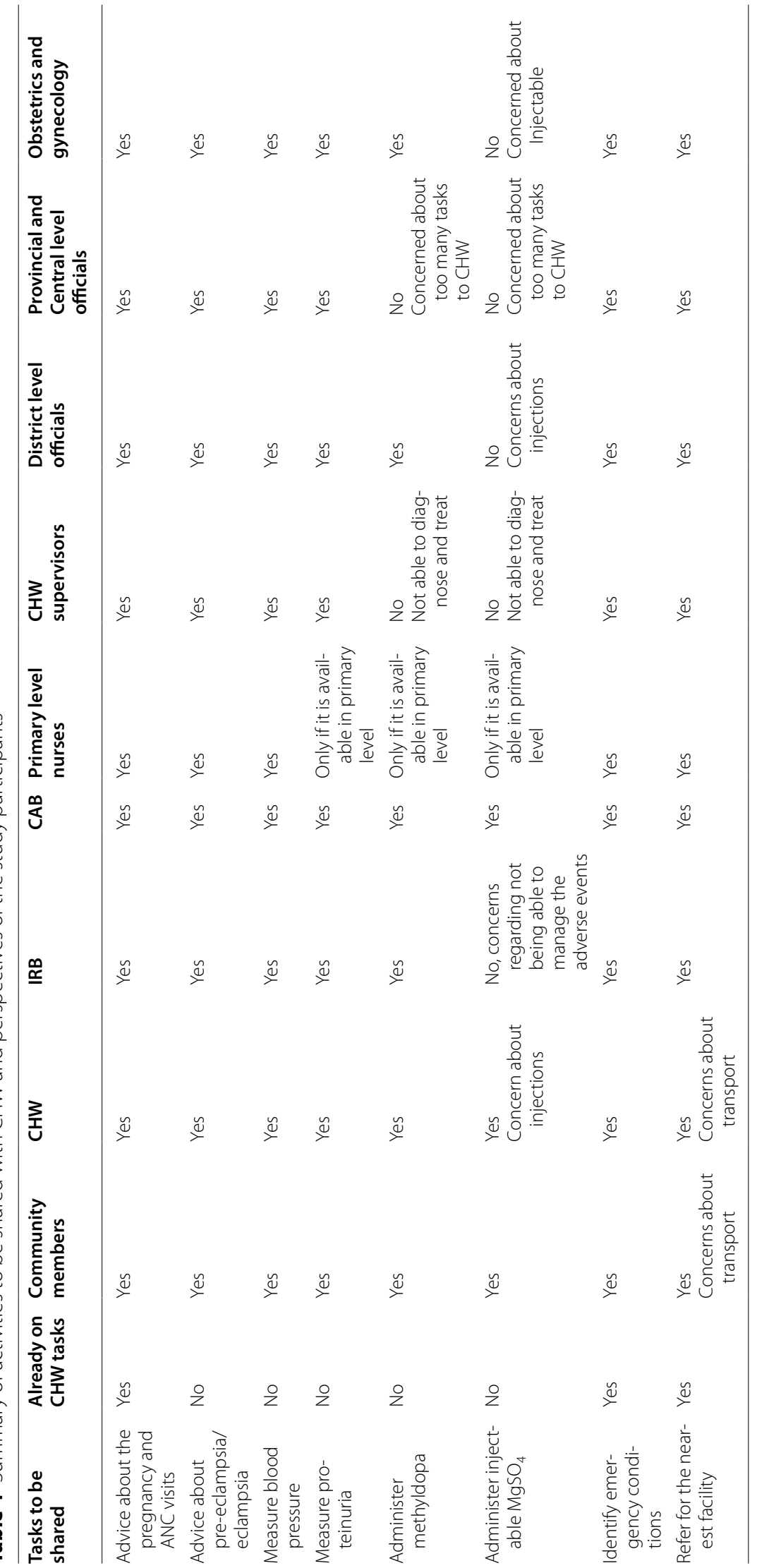


CHWs were confident delivering more interventions, and the community also accepted their role. The study showed that CHWs are well received in their communities and felt empowered with new interventions. Gender preference of CHWs was explored in this study; however, it was not found to be a concern. Nevertheless, this should be interpreted with caution as it may not be generalizable across the country [47]. The concern of CHW regarding lack of transport from the community to the health facility was aligned with what was reported by the community. This challenge needs to be addressed urgently' as the intervention is pointless if the women are unable to reach the health facilities for further management of the condition. However, in the context of delays in transportation, commencing treatment of eclampsia sooner though the CHWs may cause less harm than if $\mathrm{MgSO}_{4}$ was only be administered at the health facility [14]. Further research demonstrating the ability of CHWs to implement complex intervention would increase the acceptability of the task-sharing by $\mathrm{MoH}$ and gynaecologist.

\section{Limitations}

Facility assessment reflects one point in time and does not represent what is available at all time. The availability of equipment, for example, the blood pressure machine, does not indicate that the nurses are using it correctly for PE/E diagnosis. The qualitative data were collected in four communities in Maputo and Gaza Provinces; although these areas show a good representation of the region, results may not be generalizable to other context than the areas involved in this study. Due to the translation of the data (between Changana, Portuguese and English), some subtleties of meanings may have been lost; however, strict quality control steps were put in place throughout the transcription, translation and coding processes to minimize this limitation.

We could not interview all CHWs in the study area; some were the hardest to reach, and we lost the opportunity to have their thoughts. However, other CHW from the same location were included, which minimized the risk of affecting our results.

The decision to not involve TBAs in the intervention trial led to miss information regarding the acceptability of this group to the proposed task-sharing.

\section{Conclusions}

This study showed that task-sharing of initial screening and pre-referral management of pre-eclampsia and eclampsia is deemed feasible and acceptable by the community. But an effort should be in place to remove barriers at the health system level. There is a need to mitigate stakeholder perceptions of CHWs' inability for complex tasks. Studies to assess CHWs' ability to administrate $\mathrm{PE} / \mathrm{E}$ intervention are needed before implementing task-sharing.

\section{Abbreviations \\ AMOG: Associação Moçambicana de Ginecologistas; ANC: Antenatal care; CHW: Community health workers; CISM: Centro de Investigação em Saúde da Manhiça; CLIP: Community level interventions for pre-eclampsia; FGD: Focus group discussions; FIGO: International federation of gynaecologists and obste- tricians; HIV: Human immunodeficiency virus; iCCM: Integrated community case management; IDI: In-depth interviews; LMICs: Low and middle-income countries; $\mathrm{MgSO}_{4}$ : Magnesium sulphate; MMR: Maternal mortality rate; PE/E: Pre-eclampsia/eclampsia; PHC: Primary health care; UNICEF: United Nations Children's Fund; WHO: World Health Organization.}

\section{Acknowledgements}

The authors would like to thank all participants in the study. They also acknowledge the contributions of the Community Level Interventions for Pre-eclampsia (CLIP) Feasibility Working Group: Rosa Pires, Zefanias Nhamirre, Rogério Chiaú, Analisa Matavele, Adérito Tembe, Lina Machai, Beth Payne, Sharla Drebit, Chirag Kariya and Laura Magee. We also acknowledge the support of Manhiça Health Research Center (CISM), University of British Columbia (UBC), Maputo Provincial Health Department (DPS Maputo), Gaza Provincial Health Department (DPS Gaza), Mozambican Obstetrics and Gynecology Association (AMOG), Faculty of Medicine of the Eduardo Mondlane University, Ministry of Health (MISAU), National Direction for Public Health, and Community Health Workers Programme. This work is part of the University of British Columbia PRE-EMPT (Pre-eclampsia/Eclampsia, Monitoring, Prevention and Treatment) initiative supported by the Bill \& Melinda Gates Foundation. CISM is funded by Agencia Española de Cooperación Internacional para el Desarrollo.

\section{Authors' contributions}

ES led the analysis of the data and drafted the manuscript. HB had responsibility for data collection, adaptation of the data tools, support the analysis and interpretations of the qualitative data. KM, MV, PvD contributed to study design and provided critical manuscript revision and insight during the writing process. KM provided oversight of the manuscript. All authors, ES, HB, $M V, A V, S M, O A, Q F, C B, E M, M S$, PVD and KM participated in the interpretation of the study results and revision of the manuscript. All authors read and approved the final manuscript.

\section{Funding}

This work was financially supported by the University of British of Columbia PRE-EMPT (Pre-eclampsia-Eclampsia, Monitoring, Prevention and Treatment), a grantee of the Bill and Melinda Gates Foundation (Grant number: OPP1017337 to PvD).

\section{Availability of data and materials}

The datasets used and analysed during this study will be stored at the CISM repository and are available by request to the corresponding author after adhering to the CISM policy on data sharing.

\section{Declarations}

\section{Ethics approval and consent to participate}

Ethical approval for this study was granted by the CISM Institutional Bioethics Committee (CIBS_CISM/08/2013) and the University of British Columbia in Canada ( $\mathrm{H} 12-00132)$. All the following procedures were approved by the above mentioned committee: written informed consent was obtained from each participant before the interview and after a detailed verbal explanation of the consenting process. For the illiterate participants, a literate witness was involved in the consent process whereby they were asked to read and explain to the participant the contents of the participant information sheet. The consent form was signed by the witness and the researcher assistant after the participant's fingerprint was taken. Identifiable data of participants were 
anonymised through attribution of unique identification numbers or pseudonyms to guarantee anonymity.

\section{Consent for publication}

Not applicable.

\section{Competing interests}

The authors declare that they have no competing interests.

\section{Author details}

${ }^{1}$ Maternal Health Unit, Centro de Investigação em Saúde da Manhiça (CISM), Manhiça, Mozambique. ${ }^{2}$ Department of Physiologic Science, Clinical Pharmacology, Faculty of Medicine, Universidade Eduardo Mondlane, Maputo, Mozambique. ${ }^{3}$ Department of Obstetrics and Gynaecology, and The Child and Family Research Unit, University of British Columbia, Vancouver, BC, Canada. ${ }^{4}$ Department of Community Health, Faculty of Medicine, Universidade Eduardo Mondlane, Maputo, Mozambique. ${ }^{5}$ Ministério da Saúde, Maputo, Mozambique. ${ }^{6}$ Hospital Central de Maputo, Maputo, Mozambique. ${ }^{7}$ King's College London, London, UK.

Received: 16 March 2020 Accepted: 24 June 2021

Published online: 06 July 2021

\section{References}

1. United Nations. Millenium development goals report. New York; 2007.

2. WHO, UNICEF, UNFPA and World Bank. Trends in maternal mortality 1990 to 2015. World Health Organization 2015.

3. United Nations General Assembly. Transforming our world: the 2030 agenda for sustainable development. 2015 [Internet]. Vol. 16301. 2015. https://www.un.org/ga/search/view_doc.asp?symbol=A/RES/70/1\& Lang $=\mathrm{E}$.

4. Instituto Nacional de Estatistica. Mozambique Nacional Census report. Maputo; 2007.

5. Instituto Nacional de Estaistica. IV Recenseamento Geral Da População e Habitação. Maputo; 2017.

6. David E, Machungo F, Zanconato G, Cavaliere E, Fiosse S, Sululu C, et al. Maternal near miss and maternal deaths in Mozambique: a crosssectional, region-wide study of 635 consecutive cases assisted in health facilities of Maputo province. BMC Pregnancy and Childbirth 2014, 14:401 [cited 2018 May 18];1-8. https://www.ncbi.n/m.nih.gov/pmc/articles/ PMC4269100/pdf/12884_2014_Article_401.pdf.

7. Menendez C, Romagosa C, Ismail MR, Carrilho C, Saute F, Osman N, et al. An autopsy study of maternal mortality in Mozambique: the contribution of infectious diseases. PLoS Med. 2008:5(2):0220-6.

8. Granja AC, Machungo F, Bergstrom S. Avoidability of maternal death in Mozambique: audit and retrospective risk assessment in 106 consecutive cases. Afr J Heal Sci. 2000;7(3-4):83-7.

9. Duley L, David H-S. Magnesium sulphate versus phenytoin for eclampsia. Cochrane Database Syst Rev. 2003;(Art. No.: CD000128).

10. Duley L, Gülmezoglu A, David H-S. Magnesium sulphate and other anticonvulsants for women with pre-eclampsia. Cochrane Database Syst Rev. 2003;(Art. No.: CD000025.).

11. TMTC Group. Do women with pre-eclampsia, and their babies, benefit from magnesium sulphate? The Magpie Trial: a randomised placebocontrolled trial. Lancet. 2002:359:1877-90.

12. Duley L. Evidence and practice: the magnesium sulphate story. Best Pr Res Clin Obs Gynaecol. 2005;19:57-74.

13. Ferrinho P, Sidat M, Goma F, Dussault G. Task-shifting: experiences and opinions of health workers in Mozambique and Zambia. Hum Resour Health. 2012;10(1):34.

14. Munguambe K, Boene H, Vidler M, Bique C, Sawchuck D, Firoz T, et al. Barriers and facilitators to health care seeking behaviours in pregnancy in rural communities of southern Mozambique. Reprod Health. 2016;13(1).

15. Keyes EB, Parker C, Zissette S, Bailey PE, Augusto O. Geographic access to emergency obstetric services: a model incorporating patient bypassing using data from Mozambique. BMJ Glob Heal. 2019;4:772. https://doi.org/ 10.1136/bmjgh-2018-000772.
16. Chavane LA, Bailey P, Loquiha O, Dgedge M, Aerts M, Temmerman M. Maternal death and delays in accessing emergency obstetric care in Mozambique. BMC Pregnancy Childbirth. 2018;18(1).

17. Ukah UV, Payne B, Lee T, Magee LA von DP fullPIERS and miniPIERS WG. External validation of the fullPIERS model for predicting adverse maternal outcomes in pregnancy hypertension in low- and middle-income countries. Hypertension HYPERTENSIONAHA. 2017;69(4):705-11.

18. Bennett S, George A, Rodriguez D, Shearer J, Diallo B, Konate M, et al. Policy challenges facing integrated community case management in Sub-Saharan Africa. 2014;19(7):872-82.

19. Chilundo BGM, Cliff JL, Mariano ARE, Rodríguez DC, George A. Relaunch of the official community health worker programme in Mozambique: Is there a sustainable basis for iCCM policy? Health Policy Plan. 2015:30:ii54-64.

20. Ejembi CL, Norick P, Starrs A, Thapa K. New global guidance supports community and lay health workers in postpartum hemorrhage prevention. Int J Gynecol Obstet. 2013;122(3):187-9. https://doi.org/10.1016/j. ijgo.2013.05.001.

21. Rao VB, Schellenberg D, Ghani AC. Overcoming health systems barriers to successful malaria treatment. Trends Parasitol. 2013;29(4):164-80. https:// doi.org/10.1016/j.pt.2013.01.005.

22. Nelson R. Combating global health worker shortages. Task shifting and sharing may provide one solution. AJN Reports. 2012;112(12):17-8.

23. Khowaja AR, Qureshi RN, Sawchuck D, Oladapo OT, Adetoro OO, Orenuga EA, et al. The feasibility of community level interventions for pre-eclampsia in South Asia and Sub-Saharan Africa: a mixed-methods design. Reprod Health. 2016;13(1).

24. Sevene E, Sharma S, Munguambe K, Sacoor C, Vala A, Macuacua S, et al. Community-Level interventions for Pre-eclampsia (CLIP) in Mozambique: a cluster randomised controlled trial. Pregnancy Hypertens. 2020;21:96105. https://doi.org/10.1016/j.preghy.2020.05.006.

25. von Dadelszen P, Bhutta ZA, Sharma S, Bone J, Singer J, Wong H, et al. The Community-Level Interventions for Pre-eclampsia (CLIP) cluster randomised trials in Mozambique, Pakistan, and India: an individual participant-level meta-analysis. Lancet [Internet]. 2020;396(10250):55363. https://linkinghub.elsevier.com/retrieve/pii/S0140673620311284.

26. Mozambique M of H of. Plano Estrategico para o Sector da Saude -PESS. Maputo, Mozambique, Ministry of Health (MISAU). Maputo, Moçambique; 2007.

27. MISAU. Anuário Estatístico de Saúde 2019. 2020;1-59. http://www.misau. gov.mz/index.php/anuarios-estatistico.

28. Feldacker C, Chicumbe S, Dgedge M, Augusto G, Cesar F, Robertson $M$, et al. Mid-level healthcare personnel training: an evaluation of the revised, nationally-standardized, pre-service curriculum for clinical officers in Mozambique. 2014;9(7):1-9.

29. Mozambique R of. Lei do Trabalho (Lei 23/2007 de 01 de Agosto). Artigo 108. Maputo, Moçambique; 2007.

30. Africa S. Country Profile : Mozambique Country Profile : Mozambique. Development. 1987;(October 2014):1-4.

31. MISAU. Programa de Revitalização dos Agentes Polivalentes Elementares. 2010.

32. Gloyd S, Floriano F, Midwife MS, Chadreque MA, Nyangezi JM, Platas A. Impact of traditional birth attendant training in Mozambique: a controlled study. J Midwifery Womens Health. 2001;46(4):210-6. https://doi. org/10.1016/S1526-9523(01)00142-8.

33. Sacoor C, Payne B, Augusto O, Vilanculo F, Nhacolo A, Vidler M, et al. Health and socio-demographic profile of women of reproductive age in rural communities of southern Mozambique. [cited 2018 Feb 7]; https:// doi.org/10.1371/journal.pone.0184249.

34. Macuácua S, Catalão R, Sharma S, Valá A, Vidler M, Macete E, et al. Policy review on the management of pre-eclampsia and eclampsia by community health workers in Mozambique. [cited 2019 Aug 12]; https://doi. org/10.1186/s12960-019-0353-9.

35. Boene $\mathrm{H}$, Vidler M, Augusto $\mathrm{O}$, Sidat M, Macete $\mathrm{E}$, Menéndez C, et al. Community health worker knowledge and management of pre-eclampsia in southern Mozambique. Reprod Health. 2016;13(S2):105. https://doi.org/ 10.1186/s12978-016-0220-2.

36. Harris PA, Taylor R, Thielke R, Payne J, et al. NIH Public Access. 2010;42(2):377-81 
37. World Health Organization. Task Shifting: rational redistribution of tasks among health workforce teams-global recommendations and guidelines. World Health Organization. 2008.

38. Sevene E, Lewin S, Mariano A, Woelk G, Oxman AD, Matinhure S, et al. System and market failures: the unavailability of magnesium sulphate for the treatment of eclampsia and pre-eclampsia in Mozambique and Zimbabwe. Br Med J. 2005;331(7519).

39. Solnes Miltenburg A, Kiritta RF, Bishanga TB, van Roosmalen J, Stekelenburg J. Assessing emergency obstetric and newborn care: can performance indicators capture health system weaknesses? BMC Pregnancy Childbirth. 2017;17(1):92. https://doi.org/10.1186/s12884-017-1282-z.

40. Payne B, Magee LA, Côté AM, Hutcheon JA, Li J, Kyle PM, Menzies JM, Moore MP, Parker C, Pullar B, von Dadelszen PWB. PIERS proteinuria: relationship with adverse maternal and perinatal outcome. J Obs Gynaecol Can. 2011;33(6):588-97.

41. Waiswa P, Pariyo G, Kallander K, Akuze J, Namazzi G, Ekirapa-Kiracho E, et al. Effect of the Uganda Newborn Study on care-seeking and care practices: a cluster-randomised controlled trial. [cited 2020 Jan 2]; https:// doi.org/10.3402/gha.v8.24584.

42. Chavane L, Dgedge M, Degomme O, Loquiha O, Aerts M, Temmerman M. The magnitude and factors related to facility-based maternal mortality in Mozambique. J Obstet Gynaecol (Lahore). 2017. https://doi.org/10.1080/ 01443615.2016 .1256968$.

43. Ooms Gl, Kibira D, Reed T, Van Den Ham HA, Mantel-Teeuwisse AK, Buckland-Merrett G. Access to sexual and reproductive health commodities in East and Southern Africa: a cross-country comparison of availability, affordability and stock-outs in Kenya, Tanzania, Uganda and Zambia. BMC Public Health. 2020;20(1):1-14.

44. Fulton BD, Scheffler RM, Sparkes SP, Auh EY, Vujicic M, Soucat A. Health workforce skill mix and task shifting in low income countries: a review of recent evidence. Hum Resour Health [Internet]. 2011;9(1):1. http://www. human-resources-health.com/content/9/1/1.

45. Smith S, Deveridge A, Berman J, Negin J, Mwambene N, Chingaipe E, et al. Task-shifting and prioritization: a situational analysis examining the role and experiences of community health workers in Malawi. 2014;12(1):1-13.

46. Dawson AJ, Buchan J, Duffield C, Homer CSE. Task shifting and sharing in maternal and reproductive health in low-income countries: a narrative synthesis of current evidence. 2014;(May 2013):396-408.

47. Mariano BA, Chilundo B, Cliff J. Faculty of medicine community health department policy analysis of integrated community case management for childhood illnesses and newborn care case study of Mozambique_ draft pre final. 2012

48. Smith JM, Gubin R, Holston MM, Fullerton J, Prata N. Misoprostol for postpartum hemorrhage prevention at home birth: an integrative review of global implementation experience to date. BMC Pregnancy Childbirth [Internet]. 2013;13(1):44. http://www.pubmedcentral.nih.gov/articleren der.fcgi?artid $=3598986 \&$ tool=pmcentrez\&rendertype $=$ abstract.

49. Wells E, Coeytaux F, Azasi E, Danmusa S, Geressu T, McNally T, et al. Evaluation of different models of access to misoprostol at the community level to improve maternal health outcomes in Ethiopia, Ghana, and Nigeria. Int J Gynecol Obstet [Internet]. 2016 [cited 2017 Apr 5];133(3):261-5. http:// www.sciencedirect.com/science/article/pii/S002072921630100X.

50. Stanback J, Mbonye AKBM. Contraceptive injections by community health workers in Uganda: a nonrandomized community trial. Bull World Heal Organ. 2007:85(10):768-73.

51. Brunie A, Hoke TH, Razafindravony B. [Community-based distribution of injectable contraceptives in an African setting: community trial in Madagascar]. Sante [Internet]. 2011;21(1):21-6. http://www.jle.com/fr/revues/ san/e-docs/la_distribution_a_base_communautaire_de_contracept ifs_injectables_dans_le_contexte_africain_essai_en_communaute_a_ madagascar_289179/article.phtml?tab=texte.

\section{Publisher's Note}

Springer Nature remains neutral with regard to jurisdictional claims in published maps and institutional affiliations.
Ready to submit your research? Choose BMC and benefit from:

- fast, convenient online submission

- thorough peer review by experienced researchers in your field

- rapid publication on acceptance

- support for research data, including large and complex data types

- gold Open Access which fosters wider collaboration and increased citations

- maximum visibility for your research: over $100 \mathrm{M}$ website views per year

At BMC, research is always in progress.

Learn more biomedcentral.com/submissions 